\title{
MESTRADO MODALIDADE PROFISSIONAL: EM BUSCA DA IDENTIDADE
}

\section{RESUMO}

Este artigo pretende identificar e analisar elementos importantes no debate acerca da identidade dos programas de Mestrado Modalidade Profissional em Administração (MPA) no Brasil. A partir de uma perspectiva geral sobre os tipos de demanda mobilizados pelos programas de formação gerencial mais difundidos no Brasil (pós-graduação lato sensu, ou Especialização, e stricto sensu, nas formas de Mestrado Acadêmico e Mestrado Modalidade Profissional), procura caracterizar as condições de resposta de cada um deles às perspectivas de tais demandas. Ao mesmo tempo, introduz nesse debate a noção de competência, considerando-a como um elemento-chave para a avaliação da efetividade desses programas. Finalmente, analisa as vantagens diferenciais dos MPAs face ao atual contexto de negócios e destaca a questão da noção de competência em tal processo. $\mathrm{O}$ artigo conclui identificando as razões que têm estimulado sua forte disseminação no espaço dos programas de formação gerencial.

\section{Roberto Ruas \\ PPGA/EA/UFRGS}

\begin{abstract}
This paper intends to identify and analyze important issues in the discussion about the Executive Master Programs (Mestrado Modalidade Profissional, MPA) in Brazil. Starting with a general view about the requirements that motivate the executive development programs more important in Brazil (Lato Sensu Postgraduate or Certificate Level Programs and Stricto Sensu Postgraduate or Master of Science and Executive Master Business Administration Programs), it characterizes the response conditions by each one of them related to these requirements. At the same time, it introduces the notion of competence as a key issue to evaluate the effectiveness of these programs. Finally, based on these issues and characterizing the advantages of MPA programs, it concludes by identifying the reasons that have stimulated its strong dissemination in the general executive development programs.
\end{abstract}

PALAVRAS-CHAVE Mestrado Modalidade Profissional, formação gerencial, competências, ambiente de negócios, desempenho. KEY WORDS Professional Master Program, executive development, competencies, business environment, performance. 


\section{INTRODUÇÃo}

A face mais visível do ambiente de negócios é a intensificação da concorrência. Mas outros aspectos menos visíveis são também fundamentais na configuração desse ambiente, como, por exemplo, a difusão de uma espécie de "cultura da mudança". No desdobramento de tal ambiente, além da forte insegurança face à instabilidade de suas posições nas organizações, os gestores parecem valorizar a formação gerencial como uma espécie de resposta às expectativas que enfrentam na empresa. Dentre os programas de formação mais procurados nessas circunstâncias destacam-se aqueles de caráter mais formal, isto é, cursos de pós-graduação lato sensu (Especialização - ou "MBA de propaganda") e stricto sensu (Mestrados Modalidade Profissional em Administração - "MBAs de verdade"). Essa segunda vertente, a dos Mestrados Modalidade Profissional em Administração - MPAs -, tem sido alvo de uma procura e uma aceitação bastante grandes, especialmente por profissionais já estabelecidos na carreira. O que parece estar por trás dessa demanda é a aparente predisposição entre indivíduos e empresas por programas de formação gerencial direcionados às problemáticas empresariais efetivas. Entretanto, considerando-se a pequena experiência relativa com esse tipo de programa no Brasil, entendemos que é necessário apreender mais acerca de sua identidade a fim de compreender melhor suas especificidades e relações com outros programas de formação gerencial.

Mas o que são os programas MPAs? Trazem eles algo novo e específico relativamente aos outros programas de formação gerencial ou recorrem a velhas fórmulas? Qual é o perfil do profissional que os procura? Quais diferenciais apresentam esses MPAs em relação a outros programas de formação gerencial? Essas e outras questões semelhantes vão ser tratadas a seguir como uma contribuição para um debate mais amplo acerca dos MPAs, debate que, esperamos, deve estimular algum avanço na construção de sua identidade.

Entretanto, cabe antecipar que a base empírica deste trabalho não é ainda a pesquisa abrangente e representativa que seria capaz de conduzir a conclusões mais estruturais. De qualquer forma, na ausência dessa base de dados, entendemos ter reunido informações e conhecimentos suficientes para desenvolver nossa contribuição por meio das seguintes fontes:

a) pesquisa realizada por e-mail entre egressos das turmas

1998, 1999 e 2000 do MPA da UFRGS;

b) pesquisa realizada diretamente junto aos então partici- pantes das turmas 1999 e 2000 do MPA da Escola de Administração da UFBA;

c) Informações cadastrais acerca de sete turmas de MPAs e um número grande de turmas de pós-graduação lato sensu (Especialização);

d) contato direto em classes regulares com mais de 300 alunos desses programas.

\section{AMBIENTE DE NEGÓCIOS, A EXPECTATIVA ACERCA DO DESEMPENHO DOS GESTORES E A FORMAÇÃO GERENCIAL}

O ambiente de negócios tem se caracterizado por uma dinâmica na qual o mais visível e importante parece ser velocidade, tecnologia, expansão e interdependência internacional, concentração de capitais via aquisições e fusões, homogeneização de processos e produtos e, muito flagrante no espaço organizacional, o enxugamento das empresas. Desse contexto resulta um forte processo de intensificação da concorrência, e, em conseqüência, as empresas passam a buscar elementos que as diferenciem no mercado.

Olhando pela perspectiva dos profissionais que atuam nessas empresas, não há como não perceber que esse contexto altamente competitivo acaba por gerar um forte impacto sobre o ambiente das organizações e sobre a atuação dos gestores - a chamada "pressão por resultados". É essa pressão que, por sua vez, vai determinar uma grande expectativa sobre o desempenho dos gestores e sobre sua eficácia como liderança. Para a maior parte deles, a pressão e a expectativa transformam-se em fonte de tensão e estresse.

Mas que tipo de expectativas são essas? Tomemos os segmentos mais dinâmicos da economia, e, dentro deles, o setor de serviços propriamente dito, isto é, finanças, telecomunicações, comércio varejista etc., e os segmentos prestadores de serviços para a indústria ou para a agricultura - logística, comércio internacional, marketing etc. Nas atividades que estão sujeitas a um maior fluxo de mudanças (serviços que apresentam ciclos de vida mais curtos, relacionamento direto e intenso com clientela forte influência de oscilações cambiais e /ou de bolsas de valores etc.), a expectativa acerca da atuação dos gestores tende a ser mais intensa e rigorosa. Além disso, desconsideradas as barreiras à entrada sob a forma de capital e tecnologia, esses segmentos caracterizam-se por vantagens concorrenciais menos duradouras e, portanto, sofrem uma grande pressão por diferenciação do tipo contextual ou de curto prazo. Dos gesto- 
res que atuam nesses segmentos, espera-se, no mínimo, conhecimentos técnicos e do ambiente, habilidade para agir com desenvoltura e flexibilidade, e, ainda, disposição e talento para passar da percepção à ação por meio de respostas "confiáveis e rápidas".

Mesmo entre os setores considerados mais tradicionais em função da maturidade de suas tecnologias de produção, a concepção de estabilidade e de baixo índice de mudanças não pode ser estendida a seus processos de geração de produtos, nem ao relacionamento comercial nacional ou internacional e tampouco às áreas de marketing, propaganda etc. Em tais atividades, embora associadas à tecnologias mais tradicionais, conhecimento, agilidade e flexibilidade são elementos fundamentais. E, de seus gestores, espera-se uma atuação compatível.

Finalmente, cabe destacar as atividades que se vinculam ao espaço internacional de negócios, que, independentemente do segmento no qual estão localizadas, incluem dimensões multiculturais, além, é claro, de diferentes elementos nos campos político, social e tributário. Tudo isso significa maior complexidade e maior dificuldade na análise de situações e problemas e na tomada de decisão, o que também resulta em maiores expectativas em termos de capacitação e desempenho gerencial.

Assim, seja pela dinâmica do ambiente empresarial neste período de intensa competitividade - pressão por resultados e "cultura da mudança" -, seja pelas características específicas da competição em alguns segmentos como o de serviços, por exemplo - que requerem aptidão à mudança, velocidade, respostas "confiáveis e rápidas" e, ainda, capacidade de se diferenciar, a expectativa acerca do desempenho gerencial parece ser muito alta.

Uma revisão de recentes pesquisas realizadas junto a dirigentes de empresas sobre o que consideram o perfil ideal para seus executivos reforça a visão acima: as listagens de competências que esses candidatos deveriam, em tese, poder colocar em ação são tão amplas que ninguém menos do que um "super-homem" seria capaz de desempenhá-las adequadamente. E no topo das listagens aparece de forma quase unânime a competência "orientar-se para resultados" (Ruas, 2000).

É nesse quadro de expectativa generalizada em torno de perfis de gestores adequados às condições do mundo dos negócios que os programas de formação gerencial aparecem como alternativa importante (às vezes até como panacéia), tanto para esses gestores reagirem de forma "positiva" à pressão e ao estresse que recaem sobre eles, como para as empresas acrescentarem alternativas para sua problemática de concorrência. Mas que tipo de cur- so pode responder, mesmo que parcialmente, a essa enorme expectativa? Que tipo de programa de formação pode garantir um salto qualitativo tão consistente em termos de desempenho?

Antes de tratar mais diretamente dessa questão, vamos acrescentar um novo e fundamental ingrediente neste debate: a noção de "competência". Isso porque a noção de competência irá nos permitir estabelecer a relação imprescindível entre a dimensão "formação" (própria aos cursos mais convencionais) e a dimensão "atuação" (própria às práticas profissionais). Além disso, poderá contribuir com uma perspectiva mais realista em termos de uso dos conceitos de desempenho e competência.

\section{PROGRAMAS DE FORMAÇÃO GERENCIAL E A NOÇÃO DE COMPETÊNCIA}

Não há dúvida de que a expressão "competência" tem sido, ao mesmo tempo, uma das mais empregadas e uma das mais controvertidas no jargão da administração contemporânea. Tanto nas empresas quanto no mundo acadêmico, muitos entendem estar tratando da noção de competência, mas, de fato, estão recorrendo a outros conceitos, como os de qualificação, atribuições, performance, desempenho e objetivos.

Nesse ambiente de diferentes entendimentos, um dos poucos aspectos convergentes é o conceito de "recursos de competência". Com base na "escola francesa" que relaciona o conceito de competência à sociologia e à economia do trabalho, a disposição abaixo parece ter conseguido uma grande difusão nos meios empresariais e acadêmicos, sustentada em três elementos fundamentais:

- saber (conhecimentos) - Exemplos: estratégia empresarial, métodos de pesquisa de mercado; cultura e legislação acerca do consumo em uma certa região;

- saber-fazer (habilidades) - Exemplos: mobilização de grupos no desenvolvimento de projetos; coordenação de processos de planejamento estratégico; orientação da equipe para ampliar o relacionamento com clientes;

- saber ser/agir (atitudes) - Exemplos: reconhecimento de seus próprios erros; percepção e identificação de estados de insatisfação na equipe coordenada; capacidade de avaliar antecipadamente os impactos de iniciativas e medidas junto a clientes.

A partir dessa lógica, observou-se uma importante revisão da noção de competência: ela não seria um estado de formação educacional ou profissional, tampouco 
um conjunto de conhecimentos adquiridos ou de capacidades apreendidas, mas seria, isso sim, a mobilização e a aplicação dos recursos - conhecimentos, habilidades e atitudes em uma situação específica, na qual se apresentam condições e restrições próprias (Boterf, 1995).

Em outras palavras, com base nessa noção de competências, expressa-se uma composição dinâmica entre conhecimentos, habilidades e atitudes, composição cuja definição vai depender das características da situação na qual a competência é colocada em ação. Assim, em determinadas situações gerenciais, como, por exemplo, na concepção de um processo de planejamento estratégico, o aspecto "conhecimento" predominaria na composição; posteriormente, já no decorrer desse mesmo processo, a habilidade para conduzi-lo com envolvimento de todos os níveis gerenciais vai, com certeza, ser mais importante do que o conhecimento; finalmente, na fase de implementação em toda a organização, a atitude sob a forma de comprometimento com o processo - vai ter certamente um papel mais importante que os outros recursos - conhecimento e habilidade.

Como se pode observar, a noção de competência aqui compartilhada constitui algo maior do que uma mera descrição de atividades a realizar, pois carrega consigo uma definição do que é necessário fazer para atingir um desempenho gerencial esperado. Isso pressupõe flexibilidade, aptidão à mudança e adequação às circunstâncias, elementos muito apropriados ao contexto econômico atual.

Em síntese, as principais referências da noção de competências passariam pelos seguintes pontos:

- A expressão "competência" está vinculada à ação propriamente dita e não ao potencial para realizá-la. Ao tratar do potencial, estamos nos referindo aos recursos de competência (conhecimento, habilidade e atitude).

- A competência estaria, portanto, associada ao resultado da mobilização desses recursos.

- A efetividade e a legitimação da competência somente ocorre em situação real de trabalho, ou seja, em condições específicas do ambiente de trabalho. Em outras palavras: ninguém pode ser competente a priori (Boterf, 1995).

- Competências definidas de formas mais genéricas, mais amplas, tratando daquilo que é esperado, são mais compatíveis com o estado atual do trabalho: multifuncional, abrangente e flexível (ao contrário da tendência especialista).

- Segundo Fandt (apud Wood Jr. e Picarelli Fº 1999 , p.135), "as competências gerenciais são inter-relacionadas e construídas umas sobre as outras como uma teia complexa".

\section{Formação gerencial e desenvolvimento de competências}

Mas o que tem a ver a noção de competências com a expectativa sobre a atuação dos gestores e com os processos de formação gerencial? Ora, a maior parte dos processos de adaptação à mudança ou de inovação passam necessariamente por transformações na maneira da organização responder e relacionar-se (por meio de produtos e serviços) com seus clientes. Entretanto, obviamente, essas mudanças na relação com clientes são sustentadas por outras mudanças precedentes relativas à maneira de atuar das pessoas e dos grupos da empresa. Isso quer dizer que projetos de mudanças focados em novas formas de relacionamento com mercados e clientes (isto é, da empresa para fora) estarão associados ao desenvolvimento de competências internas, tanto em sua dimensão organizacional, quanto individual, ou seja, da empresa para dentro.

E por onde começam essas mudanças? Uma das práticas mais arraigadas na cultura das empresas é a de que os projetos de mudança começam por treinamento ou formação das pessoas envolvidas com eles. No desdobramento dessa prática, destaca-se um dos "modelos mentais" mais comuns nesse ambiente: um processo de formação é, por si mesmo, capaz de mudar a maneira de agir dos treinados; é portanto capaz de mudar suas competências. Esse princípio ainda é mais vigoroso quando se trata de programas mais longos, como os de pós-graduação lato sensu (Especialização).

Entretanto, a metodologia desses processos de formação e treinamento é, em geral, concentrada no desenvolvimento de um dos recursos da competência: o conhecimento. Embora imprescindível em um processo de mudança, a formação assim organizada não é capaz de valorizar e desenvolver certos recursos de habilidade e atitude, em geral indispensáveis à mudança e ao desenvolvimento de competências. E, embora muitos desses programas tenham sido recentemente enriquecidos com inovações importantes, o que gerou avanços na exploração do saber-fazer e até do saber ser lagir, a metodologia dos programas de formação convencional ainda continua concentrada no recurso "conhecimento", determinando um gap entre formação e competência.

Por outro lado, observa-se que parte importante desses processos de formação tende a ser desenvolvida de uma maneira relativamente distante das condições e especificidades do trabalho, ou seja, distante das condições em que as competências vão ser desenvolvidas. Aliás, uma das problemáticas mais críticas da formação coloca-se no processo de transferência e adaptação, no ambiente de trabalho, dos conteúdos do curso. 
$\mathrm{Na}$ maioria dos casos, os participantes desses programas, não conseguem, de maneira isolada e sem um apoio metodológico específico, apropriar em suas atividades as enormes potencialidades geradas entre conteúdos, exercícios e dinâmicas tratados no ambiente de formação (Ruas, 2001).

Retornando à nossa questão inicial: serão os processos de formação gerencial uma alternativa importante para responder às expectativas e pressões sobre os gestores? Como se observou acima, essa alternativa não pode ser tratada como resposta acabada. Ao contrário, é necessário avaliar e redimensionar esses programas para que se tornem mais abrangentes e, além do conhecimento, possam disseminar também o aprendizado nos campos das habilidades e atitudes. Assim, além de ampliar a relação entre formação e competências, podem contribuir para reduzir a pressão sobre os gestores e, por extensão, o estresse destes últimos.

\section{AMBIENTE DE NEGÓCIOS, EXPECTATIVAS DE DESEMPENHO GERENCIAL E OS PROGRAMAS DE FORMAÇÃO GERENCIAL MAIS CONSISTENTES}

À primeira vista, os MPAs são, no Brasil, o resultado de uma combinação de duas grandes vertentes de concepções e experiências, em termos de programas de pósgraduação orientados para a formação de gestores, além, é claro, da influência de modelos internacionais de Mestrado Executivo (os "MBAs verdadeiros"), que aportam consigo uma imagem de excelência e modernidade, mas cuja adaptação à situação da maior parte das empresas brasileiras ainda é uma incógnita.

\section{Pós-graduação lato sensu ou Especialização em Administração}

Os cursos de Especialização ou pós-graduação lato sensu em Administração, com duração mínima de 360 horas, mas que em algumas instituições chega a atingir um total de 540 horas, é um programa muito difundido no Brasil. Em geral, esses cursos propõem-se a desenvolver uma visão global acerca das principais práticas e métodos da administração contemporânea. Essa proposta visa a atender especialmente a demanda de jovens profissionais há pouco egressos de cursos de graduação, ou então de profissionais um pouco mais experientes, originários de outras áreas, como engenharia, informática, psicologia, mas que passaram a atuar em funções de gestão em período recente.
Uma outra abordagem importante dos cursos de Especialização é a de concentrar a formação em uma só função da administração, como, por exemplo, finanças, ou marketing, recursos humanos etc. Essa abordagem também agrega uma demanda importante por parte dos profissionais que já atuam em áreas específicas da administração.

Tanto em sua perspectiva mais geral, quanto na mais focada, esses programas priorizam uma visão mais generalista por meio da exposição de técnicas e ferramentas gerenciais consideradas recentes e de aplicação mais imediata. No limite, essa exposição pode ser orientada para ações de curto prazo ou, em uma linguagem mais usual, para as chamadas "receitas de bolo". Nesses casos, as metodologias empregadas não valorizam o aprofundamento, mas sim as respostas rápidas. Uma das questões mais freqüentes entre os alunos desse tipo de programa é: "como é que se pode aplicar isso?".

Nesse contexto, muito dificilmente a metodologia dos programas de Especialização em Administração poderá dar conta de um tratamento mais complexo sobre uma determinada problemática ou encaminhar o aprofundamento de um tema específico. Por essa razão, esse tipo de programa tem pouco a contribuir frente a demanda de gestores que atuem em nível mais estratégico ou costumem tratar de problemas mais sistêmicos.

Esses programas, em geral, também ficam a dever quando se trata da preparação de alguém para atuar em ambientes mais complexos e dinâmicos, ou como estímulo a propostas inovadoras e diferenciadas. E isso é, hoje, absolutamente indispensável, pois, em um ambiente quase homogêneo em termos de padrões de gestão e tecnologia, mas complexo em termos de relações econômicas, sociais e culturais, contar com gestores pensando e agindo diferentemente na organização é algo que "pode fazer a diferença".

Associando os elementos principais da noção de competência a esse debate acerca do papel dos cursos de Especialização, veremos, em primeiro lugar, que nos cursos de Especialização usa-se de maneira quase exclusiva o conhecimento como recurso de formação. Isso significa que esse tipo de programa tende, em geral, a fortalecer o gap entre formação e competência e desenvolver-se, em sua maior parte, distante do ambiente de trabalho.

\section{Programas de Mestrado Acadêmico em Administração}

Os programas de Mestrado Acadêmico em Administração são, em sua maior parte, oferecidos por universi- 
dades públicas. Seu currículo compreende, em geral, uma carga horária mínima de disciplinas e seminários da ordem de 24 créditos (360 horas) e mais uma dissertação final, na qual o aluno deve aprofundar um determinado tema associado à administração.

Esses cursos têm a pretensão de ampliar, aprofundar $e$ às vezes até redimensionar os problemas empresariais, priorizando o debate e a reflexão sobre a problemática geral do tema tratado, incluindo até mesmo dimensões históricas, políticas, econômicas e sociais. Em síntese, vai dos problemas para as problemáticas. Entretanto, no que se refere à relação com a "cultura empresarial", esses programas carregam consigo dois fatores negativos importantes: a) sua formatação, pois, em geral, exigem dedicação em tempo integral - o que inviabiliza a participação de muitos gestores que não podem, ou são impedidos de, abrir mão de suas atividades no dia a dia; e b) uma abordagem metodológica muito distante do pragmatismo associado aos problemas e às realidades intrínsecas ao mundo dos negócios. Em outras palavras, segundo essa mesma "cultura", um programa de Mestrado Acadêmico convencional não teria muito a agregar em termos de competências apropriadas à gestão no ambiente empresarial.

Entretanto, considerada a origem e natureza dos programas de Mestrado Acadêmico, essa seria justamente sua maior virtude, já que são geralmente concebidos a fim de estimular, entre os participantes, uma revisão profunda de seus conhecimentos e práticas em administração. Esse salto qualitativo propiciado pela imersão no mundo da teoria, é que constitui a base da construção de uma visão redimensionada do mundo das organizações e de suas relações com o político, o econômico e o social. Por essa razão, e a considerar as noções mais recentes de "competência gerencial", um programa de Mestrado em Administração Modalidade Acadêmica não deve ter no desenvolvimento de competências um objetivo específico.

Por outro lado, se o programa de Mestrado Acadêmico tende a aprofundar os problemas muito além de sua perspectiva pragmática, não terá necessariamente o compromisso de propor soluções

Assim, se a metodologia dos programas de pós-graduação do tipo Especialização parecem não dar conta de parte importante das atuais necessidades em formação gerencial, dada a intensificação da complexidade no ambiente de negócios, a mesma dificuldade ocorre, mas por razões muito diferentes, para o caso do Mestrado Acadêmico, cuja abordagem estaria distante da problemática empresarial.

\section{O AMBIENTE DE NEGÓCIOS E A FORMAÇÃO GERENCIAL: A CONTRIBUIÇÃO DOS MPAS}

O debate acerca da contribuição dos MPAs à formação gerencial no atual ambiente de negócios começa pela recuperação de algumas expressões já exploradas neste artigo: intensificação da concorrência, pressão por resultados, expectativas sobre o desempenho de empresas e gestores, foco em competitividade e diferenciação, desenvolvimento de competências e, por fim, formação gerencial como uma das alternativas (certamente a mais concorrida). É nesse contexto que os MPAs têm se desenvolvido.

Tomemos o caso dos chamados gerentes intermediários, especialmente os que se situam numa faixa de idade entre 30 e 35 anos. Embora sua formação gerencial mais consistente tenha se desenvolvido há relativamente pouco tempo, não podem prescindir de uma base de conhecimentos atualizados acerca de práticas e métodos recentes em administração. E se ainda não participaram nos últimos anos de um curso de pós-graduação mais longo, estão com certeza se sentindo pressionados a fazê-lo.

Até cerca de quatro anos atrás, esse gestor não tinha outras opções: um curso de Especialização em Administração, no país ou um MBA - curso de Mestrado, no exterior, pois os cursos de Mestrado Acadêmicos realizados no Brasil, como vimos acima, é uma alternativa quase impossível para esse tipo de profissional. Como a segunda opção envolveria custo alto e necessidade de permanência no exterior, restava a primeira - o curso de Especialização no país. Até nos casos em que o candidato já houvesse participado de um desses cursos, mesmo assim buscava um segundo embora parecido ao anterior. Na verdade, o que contava (e ainda conta) era estar em formação, apesar desse tipo de procedimento não o levasse a avançar muito em termos de conhecimentos e postura frente à realidade.

Conforme observamos anteriormente, algumas das recentes demandas por formação gerencial não estão sendo adequadamente atendidas pelos programas de Especialização. Estamos tratando, por exemplo, da necessidade de estimular e explorar formas de pensar e atuar de maneira diferenciada, ou seja, construir alguma coisa de pessoal; estamos tratando também da necessidade de poder lidar adequadamente com ambientes mais complexos; ou, ainda, de poder tomar decisões de forma rápida e confiável em situações pouco conhecidas. E não nos enganemos: nos dias atuais, essas situações fazem parte do universo de atuação dos gerentes médio e superior.

Por essa razão, os programas de formação de gestores que pretendam compatibilidade com o atual ambiente de 
negócios devem apropriar, em um autêntico "equilíbrio delicado", uma formação que possa dar contar de duas diretrizes em aparente oposição: rapidez e complexidade.

\section{Os MPAs e o equilíbrio delicado: rapidez e complexidade}

Que contribuições pode aportar um curso tipo MPA no contexto atual? Como forma de subsídio ao texto que segue, estamos empregando os resultados de pesquisa realizada junto a egressos das turmas de MPAs 1998, 1999 e 2000 da Escola de Administração da UFRGS.

Resposta: em primeiro lugar, a possibilidade de obter um maior aprofundamento nas questões e problemáticas da gestão empresarial, o que vai resultar nas capacidades de a) compreender e avaliar, com olhar mais crítico, as novas técnicas e ferramentas de gestão; b) de entender e analisar cenários e situações etc. E esse processo começa por um aspecto subjetivo, que é a expectativa "quase mágica" dos participantes de obterem o título de mestre. Isso acaba por gerar, senão em todos, pelo menos em muitos, o pressuposto de que seu percurso nesse programa irá lhes exigir inevitavelmente um certo aprofundamento nos temas a serem tratados, e, em conseqüência, a disponibilidade para leituras, debates e reflexões. Essa maior predisposição para leituras e reflexões também perpassa os professores dos programas, resultando que, na maioria dos casos, a exploração dos temas é mais aprofundada do que nos cursos de Especialização.

E essa condição é facilitada pela formatação mais espaçada entre um encontro e outro, já que a maioria deles fixa-os em fins de semana alternados, para uma duração total de aproximadamente 24 meses. Esse modelo torna viável a leitura de textos e documentos, bem como a realização de produtivos trabalhos em grupos, os quais tomam a forma de um excelente veículo de troca de experiências, reflexões, revisões de pressupostos e outras dinâmicas que geram aprendizagem.

O aprofundamento das questões tratadas no curso vão certamente estimular o desenvolvimento, entre os participantes, de algumas competências associadas ao atual contexto de negócios, especialmente no que se refere ao tratamento de situações mais complexas e de abrangência sistêmica. Essa lógica é confirmada na pesquisa realizada entre egressos dos MPAs, a fim de identificar o que foi efetivamente aprendido durante o curso. Pois, segundo os entrevistados, o principal aprendizado no curso foi "atuar com mais segurança e confiança em ambientes mais complexos, interdisciplinares e /ou multinacionais", prioridade que atingiu quase unanimidade entre os respondentes.

Uma segunda contribuição dos MPAs se concretiza na própria interação entre os participantes do curso -, pois é grande o número deles que já possuem uma experiência relativamente grande como gestor. Aliás, ao contrário do que ocorre em outros países, no Brasil o MPA atende parte importante do corpo gerencial médio / superior das empresas, caracterizando para esses últimos uma espécie de recuperação do tempo perdido em formação. De fato, os processos de interação entre participantes desses cursos têm gerado importantes avanços na construção de uma visão de mundo mais heterogênea e complexa, expressão das contradições atuais.

Esse aspecto é corroborado pelos resultados da pesquisa entre egressos: em segundo lugar entre os mais importantes fatores de aprendizagem aparece "estímulo a compartilhar experiência, conhecimentos e informações com as pessoas que coordena e /ou atua". Entendemos que a sistemática do curso, assim como seu cotidiano de trabalhos em grupo, constitui um grande estímulo ao desenvolvimento dessa competência.

Um exemplo desse processo foi recentemente constatado em experiência observada em MPA patrocinado por um curso de Administração de uma universidade federal brasileira. A convivência em trabalhos de aula e seminários durante grande parte do período letivo, entre gestores oriundos de três segmentos sociais (privado, público e terceiro setor) transformou as recíprocas desconfianças e preconceitos iniciais em processo de abertura e compreensão face aos universos pouco conhecidos dos outros interlocutoes. Segundo seus próprios depoimentos, os gestores do setor público entendiam que os do setor privado só se mobilizavam em função de lucros e resultados; já os do setor privado viam nos gestores do setor público um "grupo de corporativistas", que só se preocupavam com assuntos de seu próprio interesse. E, finalmente, nenhum dos dois grupos conhecia o que se pensava e fazia no chamado "terceiro setor".

Continuando o depoimento, os três grupos consideraram que a convivência e a elaboração de trabalhos em comum permitiram uma mudança substancial na maneira de ver os outros setores e até mesmo uma mudança relativa de ver o mundo. Nesse sentido, entenderam que essa convivência foi tão importante quanto as disciplinas e os conteúdos do próprio curso. Revelaram ainda que, através desse processo, mudaram sua sistemática de pensar e analisar problemas e tomar decisões a partir de uma perspectiva mais ampla dos elementos em jogo em cada uma dessas práticas, o que implicou, ainda segundo eles, na construção de uma visão mais sistêmica.

Em síntese, esse exemplo revela de uma maneira singela, mas ao mesmo tempo bastante elucidativa, as di- 
versas possibilidades de tratamento de questões no campo da administração, as quais podem ser redimensionadas durante um programa dessa natureza.

A terceira contribuição dos MPAs para seus participantes, é a capacidade de aprofundar análises e associações a fim de entender melhor os cenários e situações que se colocam no mundo real. Nesse sentido, vale destacar um outro resultado da pesquisa entre egressos, considerado muito relevante para a grande maioria dos entrevistados: "ampliar a capacidade de relacionar cenários, perspectivas, situações e variáveis de origens e naturezas diferentes". Com certeza, trata-se de um aprendizado muito importante, a fim de que um gestor possa dimensionar adequadamente a complexidade de alguns problemas e de algumas decisões que precisam ser tomadas.

Finalmente, para não deixar a questão da "rapidez" a descoberto na análise das contribuições dos MPAs ao contexto atual, podemos abrir um pequeno espaço para tratar de mais um resultado de aprendizagem considerado prioritário dentre os egressos das turmas pesquisadas: "uso de métodos mais sistemáticos em suas atividades gerenciais: resolução de problemas críticos na tomada de decisões". Esse aspecto parece-nos crucial, pois o que um egresso desse tipo de curso leva de mais importante é, com certeza, o aprendizado metodológico, ou seja, mudanças na maneira de fazer as coisas - no processo de tomada de decisões, na análise de cenários, na avaliação de problemas, no compartilhamento de projetos etc. E aí, tratando da maneira de pensar e fazer as coisas, estamos tratando da noção de competências.

\section{Os MPAs e sua necessidade de aproximar-se das condições e especificidades das situações empresariais}

No tópico anterior destacamos os resultados de pesquisa junto a egressos de MPAs, nos quais se evidenciou alguns aspectos que, segundo eles próprios, foram aprendidos durante o curso. Dentre esses destaca-se a) "atuar com mais segurança e confiança em ambientes mais complexos, interdisciplinares e /ou multinacionais"; b) "estímulo a compartilhar experiência, conhecimentos e informações com as pessoas que coordena e /ou atua"; e c) "ampliar a capacidade de relacionar cenários, perspectivas, situações e variáveis de origens e naturezas diferentes". Todos eles podem ser classificados como competências, pois traduzem uma forma de agir adequada a certas situações e circunstâncias. Mas, ao mesmo tempo, não são temas explorados em apenas uma disciplina ou em um pequeno grupo delas. Trata-se de competências resultantes de um aprendizado transversal, isto é, um aprendizado que perpassa as atividades realizadas em praticamente todas as disciplinas. Por essa razão, são chamadas de "competências transversais".

Apesar de toda a controvérsia quanto ao emprego da noção de competência, não há dúvida de que os participantes dos MPAs, assim como as empresas que em grande parte dos casos subsidiam os custos de seus gestores nesses programas, tendem a progressivamente considerar e avaliar o desenvolvimento e a apropriação de competências como um valor agregado, a exemplo do que ocorre em muitas das organizações no exterior. O desenvolvimento de competências seria, nesse caso, uma das palavras-chave de tais programas.

Aparentemente, um programa de formação sustentado em métodos de difusão de conhecimentos e informações embora indispensáveis -, não é suficiente para gerar competências. Mudanças na maneira de agir implicam, em geral, a internalização de novos conceitos e métodos, o que representa um autêntico processo de aprendizagem, conforme observamos através da pesquisa aqui apresentada.

Assim, não há como deixar de considerar a perspectiva do desenvolvimento de competências em um ambiente de MPA. Nesse caso, estaríamos avaliando sobretudo a apropriação dos conteúdos e das experiências do programa a partir da perspectiva do aluno. Ou seja, o foco do sucesso do programa estaria no que foi aprendido no âmbito das "competências" do aluno. Embora muito simples, não deixa de ser esse um enfoque quase revolucionário em termos da formação gerencial.

Experiências e atividades mais informais junto a alunos de MPAs tem apontado algumas competências que acabam sendo exploradas, segundo eles, a partir de trabalhos em grupos, na classe ou fora dela, assim como em atividades de leitura, debate e reflexão, o que tem gerado a oportunidade de desenvolvimento das seguintes competências:

- capacidade de atuar em equipe;

- desenvolvimento da capacidade de investigação e pesquisa;

- desenvolvimento da capacidade de elaboração de propostas e de novas idéias;

- capacidade de relacionar e associar;

- capacidade de atuar em interdisciplinaridade;

- capacidade de análise e avaliação de situações vivenciadas em empresas;

- habilidades na aplicação de metodologias científicas e operacionais;

- habilidades na busca de informações e conteúdos de interesse da organização;

- troca de experiências entre gestores de empresas e áreas diferentes; e

- ampliação de horizontes. 
Entretanto, a exemplo de outras experiências semelhantes, observa-se que a cultura gerencial e pedagógica predominante nestes programas tende a não considerar e muito menos valorizar o que se denominou de "aprendizagem transversal". Mas embora um produto não deliberado, não há como reduzir sua importância no contexto atual.

\section{OBSERVAÇÕES FINAIS}

Dentre as questões trazidas no decorrer deste trabalho, cuja pretensão é levantar elementos para o debate acerca da identidade dos chamados Mestrados Modalidade Profissional (MPAs), os principais destaques apresentados foram:

a) Os MPAs vêm ocupar um espaço importante no contexto da formação e desenvolvimento de gestores no Brasil - um espaço situado entre os programas de Especialização e os Mestrados Acadêmicos, já que nenhum desses dois tipos de programas pode, em nosso entender, atender de forma adequada à nova configuração de demanda por formação gerecial.

b) Certamente, as instituições que promovem esse tipo de programa não podem abrir mão de buscar a renovação e o redimensionamento das concepções e práticas dos alunos acerca de suas atividades e do mundo dos negócios. Paradoxalmente, essa revisão deve buscar elementos em processos que são historicamente típicos do Mestrado Acadêmico, como, por exemplo, leitura, reflexão e análise crítica - individual e em grupo - de textos e documentos. Processos de reflexão como esses consolidam-se em geral, a partir da elaboração escrita, por cada participante, da visão que desenvolveu acerca dos temas tratados, seguida de um processo de interação e troca entre eles.

c) Por outro lado, embora esse processo constitua a mola propulsora de uma dinâmica de crescimento pessoal e profissional, não há dúvida de que a expectativa de cada um dos participantes, ao final dos cursos MPA, é de ter apropriado, durante o percurso, algumas competências que lhe permitam expressar seu crescimento no âmbito do "mercado" no qual vai oferecer seu talento. E, nesse contexto, considerar a noção de competências como um elemento vital na concepção e organização dos MPAs parece-nos uma questão importante para a consolidação de tais programas.

d) Finalmente, observações empíricas têm mostrado que o desenvolvimento de competências, no campo de atuação desse tipo de Mestrado Profissional, parece constituir um "produto não deliberado". Entendemos, porém, que é preciso aproveitar essa oportunidade e associar esse desenvolvimento às condições e especificidades do ambiente de trabalho. Nesse sentido, uma das principais alternativas de tal processo aparece sob a forma da abordagem "aprendizagem nas organizações". Mas isso é uma outra questão e demanda um outro debate.

Artigo convidado. Aprovado em 15/02/2003.

\section{Referências bibliográficas}

BOTERF, G. De la compétence. Parisł: Les Editions d'Organisation, 1995.

BOTERF, G. Compétence et navigation professionnelle. Parisł: Les Editions d'Organisation, 1999.

BOUTEILLER, D. Le syndrome du crocodile et le défi de l'apprentissage continu. Gestion, Montreal, v. 22, n. 3, 1997.

BRANDÃO, H. P. e GUIMARÃES, T. A. Gestão de competências e gestão de desempenhos: tecnologias distintas ou instrumentos de um mesmo constructo? RAE - Revista de Administração de Empresas, São Paulo, v. 41, n. 1, p. 8-15, Jan. /Mar. 2001

FLEURY, A. C. C. e FLEURY, M. T. Estratégias empresariais e formação de competências. São Paulo: Atlas, 2000.

LEVY-LEBOYER, C. La gestion des compétences. Paris : Editions d'Organisations, 1996

PARRY, S. The quest for competence. Training, p. 48, July 1986.

PRAHALAD, C. K. e HAMMEL G. A competência essencial da corporação. In: Ulrich, D. Recursos humanos estratégicos. São Paulo : Futura, 2000.

RUAS, R. A atividade gerencial no século XXI e a formação de gestores: alguns nexos pouco explorados. Read, edição 15, v.6, n. 3, Out. 2000.

RUAS, R. Desenvolvimento de competências gerenciais e a contribuição da aprendizagem organizacional.In: Fleury, M. T. e Oliveira Jr. M. (Orgs.). Gestão estratégica do conhecimento. São Paulo : Atlas, 2001.

WOOD JR., T. e PICARELLI F ${ }^{0}$, V. Remuneração por habilidades e por competências. $2^{a}$ ed. São Paulo : Atlas, 1999.

\section{Roberto Ruas \\ Professor da Escola de Administração da UFRGS. Interesses de Pesquisa em gestão por competências, aprendizagem nas organizações e criatividade. \\ E-mail : rlruas@ea.ufrgs.br \\ Endereço: Rua Washington Luiz, 855. Porto Alegre, RS. CEP 90010-460.}

